\title{
The Psychological Autopsy as a Means to Analyse Cases of Mass-murder and Homicide-suicide
}

\author{
Andreas Frei, MD \\ Department of Forensic-psychiatric, Adult Psychiatry Basle-County, Switzerland
}

Copyright $\bigcirc 2016$ by authors, all rights reserved. Authors agree that this article remains permanently open access under the terms of the Creative Commons Attribution License 4.0 International License

\begin{abstract}
In February 2013, a 42 year-old worker in Central Switzerland shot four of his colleagues on his workplace in the canteen unexpectedly, wounded five more seriously and eventually he was shot during the event. This event called "amok" in the lay press can be classified as mass murder according to several authors. There was no apparent reason for this deed, and the perpetrator had not been a mobbing victim nor had he been treated unfairly by his supervisors at work. The district attorney ordered a psychological autopsy of the perpetrator which revealed that he had suffered from paranoid schizophrenia and acted according to his delusions of persecution. This paper discusses how to perform such an investigation. The application of psychological autopsy is strongly recommend in future similar cases.
\end{abstract}

Keywords Mass Murder, Amok, Psychological Autopsy, Schizophrenia

\section{Introduction}

Mass-murders, especially mass-shootings, are an issue also in a country like Switzerland [1] with its comparatively low prevalence of homicides [2]. The frequency of mass murders seems to have risen lately [3]. Studies about mass killers are hampered by the fact that in one third of the cases the perpetrator may commit suicide or that the researcher only had access to newspaper reports and not the official files [4], but also by the comparatively small number of cases [5]. Even if the researcher may have accessed to the official files, in the case of death of the perpetrator they might disclose only scarce information because the case might be closed as soon as it is clear that the perpetrator has died during the act [6]. Considering the fact that one of the largest epidemiological studies still relies on newspapers report, it seems that carefully executed case reports still are crucial for the understanding of this phenomena [4].

This case report is about Victor B. $\dagger$, who committed a mass-shooting in the small village of Menznau in the
Canton of Lucerne/Switzerland: The authorities had asked a posthumous forensic-psychiatric report about the state of mind of the perpetrator who had died during the event and whose motives were source of rumors and speculations. The basis of this case report were the elaborate final report of the CID of the Canton Lucerne and personal interviews of the author with some of the people involved. The names of all protagonists mentioned below were altered with the exception of the perpetrator's whose name was largely disseminated by the media.

\section{Amok, Mass-murder and Homicide-suicide}

It is quite common to designate as "amok" cases where a man (as a matter of fact, the author is only aware of one case of an independently acting female perpetrator ${ }^{1}$ ) kills or injures several people without caring for his own security. This was also quite common with the Menznau case. The designation of the Menznau case as "amok", however, is quite imprecise. "Amok" is a culture-bound syndrome, where a perpetrator develops a kind of fury and randomly kills as many people as he can reach before falling in a kind of lethargy. "Amok" as phenomenon is attributed to South-East Asia. "Amok" as a matter of fact might be a culture-bound kind of suicide, since often, perpetrators of amok do not survive the event [7] Unaffected by these facts, media still denominate such events "amok" [8].

According to Dietz [9], Mass-murder is an event where one perpetrator injures on a particular, geographically close defined place within a very short time five people, three of them lethally. For Holmes and Holmes [10], the killing of three people in a narrow geographical and time context is sufficient for the definition - this in contrast to the definition of „Serial Killer" where three people are killed with a „cooling down“ gap of at least one month between the two

\footnotetext{
${ }^{1}$ On the $22^{\text {nd }}$ of September 2010, however, a woman in the agglomeration of Basle killed in the context of a so called „Familien-Drama“ three people (Basler Zeitung 23.09.2010, S. 22).
} 
events.

Dietz [9] established three categories of mass murderers: family killings, set-and-run murderers and pseudo commandos which also referred to as rampage murderers [4].

In his paper about mass murderer, Auxmery [3] cites several papers which declare that the mental "mass murder patient does not exist". This notion is in stark contrast to Hempel and Meloys study about a random sample of 30 mass-murders in USA. Their conclusions were: The typical American Mass-murderer is a male single or divorced man in his fourth decade. Usually he suffers from an Axis I (schizophrenic or depressive) or/and an Axis II - disorder (personality with schizoid, paranoid or antisocial/narcissist traits). 10 perpetrators $(33 \%)$ were clearly psychotic at the time of the crime. The typical mass murderer is a loner with a preference for weapons, militaria or right wing ideologies, in the time before the event he suffered from a serious personal loss or frustration and hence developed a so called „Warrior-mentality“. Alcohol was in contrast to the usual violent crime of minor significance. A considerable share of the perpetrators has announced their motives in the form of a "psychological abstract" during the event [11].

\section{Mass-murder in Switzerland}

There are no scientific publications about mass-murder in Switzerland. A research of the Swiss News Agency dpa which had been performed because of the Menznau-event, revealed 22 so called "amok"- cases, i. e. a perpetrator injured and/or killed several people at one event without apparent, understandable motive like revenge, greed or jealousy. Some of these cases are described and commented below [1].

16 $^{\text {th }}$ of April 1986: Günther Tschanun, head of a section of the City-Police, after tensions on his workplace in the municipal works service in Zurich, killed four colleagues and injured a fifth one seriously. He was judged to be mentally sane and consequently condemned to 20 years of prison.

$2^{\text {th }}$ of March 2000: A 22 year old unemployed shot from a room of his hotel randomly at people and the police wounding two officers. He was killed by a police sniper. He was most probably suffering from a major mental disorder.

27th of September 2001: The 57 years old Friedrich Leibacher, frustrated by the local authorities for a minor legal case, shot in the Cantonal Parliament of the Canton Zug 14 politicians with an assault rifle and a shot-gun, before killing himself. His case shall be described in more detail in section 4.2.2. of this paper.

8th of July 2003: A 40 years old Algerian hit with his car on the street walks randomly pedestrians, killed three of them and injured seven more. He was judged not guilty by reason of insanity and put into unlimited custody.

29th of March 2004: A 43 year old famer in Escholzmatt, a village in the Canton Lucerne, shot his estranged wife, his brother, his brother-in-law and the head of social services of the said community, before killing himself. Background of the crime was heavy familiar quarrels. He had been seen by the author of this paper some months before in prison and was certainly not suffering from a major mental disorder

$2^{\text {nd }}$ of January 2013: In the small village of Daillon in the Canton Valais a 33 year old local shot randomly dead three women and heavily injured two men. According to the police, the man was known to the guardianship authorities who had, however, failed to take action against him.

As it can be seen by these few examples, perpetrators of muss murder in Switzerland show quite a divers' pattern of motives and psychopathology.

\section{Case Report}

\subsection{Final Report of the CID of the Canton Lucerne from $18^{\text {th }}$ of October 2013}

\subsubsection{First Report}

On Wednesday 27th February 2013 at 9.14 a.m., the emergency number of the Lucerne Police was urgently called because there had been a shooting in the canteen of the Kronospan in Menznau, a factory of medium size producing clamping plates. At 09.29 a.m., the first patrol car of the police reached the place; they were informed that the perpetrator had been overpowered. The officers met at the entrance of the canteen several people who were caring for some injured. In the canteen itself, they found the perpetrator, Victor B. $\uparrow$, lying on his stomach; his hands had been bound with some cable straps on his back. There was also some injured lying on the floor.

\subsubsection{Modus Operandi of Victor B. $\dagger$}

The same morning, the supervisor of Victor B. $\uparrow$ had asked him whether he could come to work outside his usual shift. Victor B. † said it was impossible since he had an appointment with his G. P., as a matter of fact he was supposed to bring his younger son at 8.30 a.m. to the g.p. for a routine consultation. Later investigations revealed that he took his small revolver which he had hidden in a steel box in the chimney. Later, his elder brother Zoran B. claimed that he had seen Victor B $\uparrow$ carrying this gun with him already on February 25th.

Victor B. $\uparrow$ drove with his Mini Cooper S from his home the $5 \mathrm{~km}$ to the factory and parked in front of it instead of driving it in the parking lot of the employees. He turned the car as if it should be ready for a quick flight; his wife, however, stated her late husband always parked this way to show to the public the nice car he possessed. He was registered by the video-cameras at the entrance; he arrived at 8.41 a.m.; he committed the act after 9.40 a.m.; it was not known what he had done during this time since he had left the range of the cameras. Several employees saw him busying with his smart phone; as a matter of fact that he 
posted on Facebook a "Renault"-advertisement with a beautiful woman and a man quite resembling Victor $\mathrm{B} \dagger$.

Then he entered the canteen. Out of the four people standing in the corridor at the entrance only one survived. This one, Mr St., had been waiting for his food before the shelter. Before him was Bruno S., a well-known and popular Swiss wrestler. Suddenly, Mr. St. heard a shot and was hit at his arm; he sunk to the floor. He heard a second shot and noticed Benno S. sinking also to the floor. He heard Ms N., the waitress scream and a third shot and lost consciousness. Before entering the canteen itself, Victor B. $\uparrow$ had already shot four times.

By entering the canteen, Victor B. $\uparrow$ kept in one hand his pistol and in the other a magazine. He immediately started shooting at the people having their second breakfast. He hit one of the employees in the head; the others realized the danger and looked for shelter behind the boards of the overturned tables. He shot at another man on the face and upper part of his body, and another man in the head (he is still in a state of coma). Several victims witnessed that Victor B. $\dagger$ changed the magazine during the action and made a loading movement.

Victor B. $\uparrow$ continued shooting at people, but not all bullets hit victims; some projectiles could be found in the frames and boards of the table. Victor B. $\dagger$ approached the last table and aimed at Markus A. who was cowering behind a table-board. Markus A. apprehended a chair with his right hand and got up; Victor B. $\dagger$ shot on his face and injured his jaw. In spite of this injury and due to blood stained glasses impaired view, Markus A. proceeded towards Victor B. $\dagger$ and hit him with the chair. He put his left arm around the right shoulder of Victor $\mathrm{B}$. $\dagger$ and flung his left arm around Victor B. †'s waist. By clinching Victor B. $\dagger$ in this way, Markus A. heard two shots very shortly one after the other: One of them penetrated his jacket in the region of the right shoulder, left and penetrated the jacket again in the region of the hip and touched his trouser - all without injuring him. The second shot hit Victor B. $\dagger$ in his head behind his right ear; the outlet was on his left temple. Victor B. $\dagger$ and Markus A. staggered to the floor, Markus A. fell on his back, Victor B. $\dagger$ came to lie on Markus A.' s stomach. Markus A. would still hold Victor B. $\dagger$. When another employee, Martin R., realized the scene, he gripped another chair and hit it several times on the back of Victor B. $\dagger$, then fled and shouted for help. Two more people entered the canteen by the window and freed Markus A. from his unpleasant position. One of them stated later as a witness, and he was sure that Victor B. $\dagger$ still held the pistol in his right hand under his belly, when he tore him from Markus A.

It is quite possible that Victor B. ${ }^{\dagger}$ tried to parry the attack of Markus A. by shooting at him. The second lethal shot hit him behind his right ear, on the edge of it there were small burns. According to the traces, the shot was fired from a very short distance.

\subsubsection{Reflections about the Kind of Victor B. †'s Death}

According to the findings of the criminal investigation team, there was no evidence that somebody else than Victor B. $\dagger$ would have fired the shot which killed him. The way Markus A. was clinched to Victor B. $\dagger$ made it quite impossible for him to apprehend his gun. And what's more, there were traces of gun smoke on the left sleeve of Markus A.'s jacket, most probably from the same shot which caused the burns on the ear of Victor B. $\dagger$. Markus A. stated as a witness that he felt the body of Victor B. $†$ lying with considerable weight on him implicating that he was already dead at this very moment.

Close to the entrance of the lethal shot, there were burns signifying that it was a relative pot-shot. Victor B. $\dagger$ was right-handed. From a coroners point of view, there were no arguments against the hypothesis that Victor B. $\dagger$ himself was the one who shot last; suicide seems quite plausible but an involuntary act in the sense of an accident cannot be ruled out. The gun of interest is a pistol Sphinx Model 389 AT 9 mm. It had been sold legally to a Mr L. M. in 1993 and had been sold 2003 to Zoran B., the brother of Victor B. $\dagger$

The revolver Victor B. $\dagger$ was carrying also with him at the time of the crime was a revolver NNA-lr (calibre 22). Victor B. $\dagger$ had bought this gun legally in 2004 .

According to the forensic evidence, Victor had shot 18 bullets. When he was stopped by Markus A., he still had four bullets in the magazine. In his right pocket he still had a pistol with five bullets. In his Jacket, there were 28 bullets for the pistol and 90 bullets for the revolver. If he had not been stopped, he probably would have injured or killed quite some more people.

\subsubsection{Reflections about the Choice of Victims}

Victor B. $†$ arrived at 7.41 p.m. at the factory compound. One might ask why he did not immediately enter the canteen and started to execute the deed. This question cannot wholly be answered. Victor B. $\dagger$, however, was a member of shift No. 4 until the end of 2012. Exactly the members of this shift had their team for the second breakfast until 8.45 a.m. and stayed in the canteen. The only member of that crew, Mr. Kurt A., was still in the canteen when Victor B. $\dagger$ started his attack. Victor B. $\uparrow$ aimed at Kurt A., who was hiding behind a turned table, but when Kurt A. started talking to Victor B. $\uparrow$, he targeted somebody else. It seemed that Victor was quite consciously spare the former mates from his shift.

\subsubsection{Biography of Victor B. $\dagger$}

Victor B. $\dagger$ was born as the third of seven children of his parents in Gjakove, in the west of the former autonomic region Kosovo of the former federal republic of Yugoslavia. His childhood and youth seemed to have been quite normal. An uncle of him, however, is said to have suffered from mental problems. He attended the elementary school for eight years and then for 1.5 years the public school which he had to leave without degree for economic problems. In $1990 / 1991$, he attended the compulsory military service in the federal Yugoslavian army and deserted from there to Switzerland, after the army had intervened in Croatia at the beginning of the Yugoslavian war. He demanded Asylum, 
which was not granted, but due to the on-going Yugoslavian crisis he got a provisional permit and worked as a waiter in Lucerne. In 1986 after having lost money with gambling, he attacked together with a colleague the cashier of a gambling place on her way home and robbed her bag containing some 1000.-Frs. He was sentenced to one year of prison on probation and a provisional expulsion from Switzerland. One year later, there was a minor case of shoplifting.

In 1997, he married Veronica, a Swiss citizen, but whose parents came from the same region of Kosovo as Victor B. $\dagger$. In the year 1999, Victor B. $\dagger$ was employed by Kronospan, then in 2001, the couple got a house in Willisau $5 \mathrm{~km}$ from the working place of Victor B. $\uparrow$. The marriage which had not been arranged was fine until the birth of the first son; the couple had three children of whom the last born is suffering from a chronic disease. Step by step the relationship between the two spouses deteriorated, since Victor B. $\dagger$ neglected his spousal duties. In general, however, he is told to have been a jolly and helpful man and gifted craftsman.

In the middle of the last decennium, he started to engage in lending quite big sums of money of dubious origin, provided by his brothers, to former fellow countrymen for interest up to $15 \%$ per month. It seems, however, that in some cases he behaved quite generously.

In 2010, he got a warning in his firm because of lack of diligence and non-compliance to some rules.

In the same year, he had an affair with the wife of a colleague; it is, however, not clear, how far this "affair" went; for his wife, however, it signified an ultimate damage to their marriage. Since then she undergoes psychotherapy with a psychologist.

Since the year 2012 even to people outside the family some changes could be noticed in the behaviour of Victor B. $\dagger$ : He started compulsively using the internet and especially Facebook, had a feeling that pictures about him would be published, felt he had dialogues with celebrities and felt his private thoughts were broadcasted by means of his mobile. He complained several times for being mobbed in Kronospan and having been spied at and clandestinely photographed, but would accuse nobody directly. In December 2012, he got an injury on his ankle, a cousin of him accompanied him to the emergency ward of the nearby regional hospital; later this cousin explained Victor B. $\dagger$ behaved in an odd way fearing there were cameras in the hospital; in the medical files of the hospital, however, there are no mental abnormalities concerning Victor B. $\dagger$ registered.

At the beginning of 2013, the direct supervisor of Victor B. $\dagger$ contacted his wife and asked, whether Victor B. $\dagger$ was suffering from a "burn-out"; his colleagues noticed that Victor B. $\dagger$ had increasing difficulty to concentrate and became forgetful; he started to talk to himself and was constantly occupied with his mobile even though it was against the rules at work. From time to time, he would perform unmotivated Kickboxing movements. When addressed he often would answer in a strange way as if he had not understood the question. The change in his behaviour was an issue in his core-family, especially for his wife, and also at his workplace, but, however, with no consequences.

On Wednesday, $27^{\text {th }}$ of February 2013, his supervisor asked Victor B. $\dagger$ whether he agreed to take over a shift of a colleague, but he denied since he had an appointment with his g. p. But instead of going there, he drove with two guns to the factory.

\subsection{Mandate for a Psychological Autopsy}

\subsubsection{Introduction}

Shortly after the event at Menznau the author of this paper as head of the local forensic-psychiatric services was mandated to produce an expertise about the mental state of the perpetrator Victor B. $\uparrow$ and to give, if possible, an expert opinion about his legal responsibility.

\subsubsection{The Psychological Autopsy}

Any expertise of this kind of course is hampered by the fact, that the perpetrator is dead and in the case of Victor B. $\dagger$ did not leave any written evidence about his motives. In 1981, Shneidman recommended in cases of an uncertain kind of death with unresolved questions from the field of insurance law or forensics the Psychological Autopsy [12]. Marzuk [13] stipulates the application of this method for the research about the phenomena of Homicide-Suicide, meaning the killing of someone with consecutive suicide of the perpetrator. The method itself consists of the examination of insurance-, police- and clinical files as well as the interrogation of friends and kin, in order to identify the kind of death (homicide, suicide, accident), respectively to understand the motive of a putative suicide. In order to express myself to the question of a putative mental order of Victor B. $\dagger$, the method of the Psychological Autopsy was applied. Even though the expert was not specifically asked for he also gave his opinion about the kind of death of Victor B. $\dagger$ (suicide, accident) and whether this event could by any means have been predicted and/or prevented).

As a matter of fact, in the case of the 57 years old Friedrich Leibacher, who entered on the $27^{\text {th }}$ of September 2001 heavily armed with automatic weapons and shotguns the cantonal parliament of the Canton Zug and killed 14 of the present politicians before shooting himself, a Psychological Autopsy had been ordered in order to understand his state of mind during the event and his legal capacity. Background of the crime was quite a banal legal quarrel about a damaged car-antenna (!) [8]. Only two weeks after the so called "Zug amok", a certain Mr. H. carrying a violin case entered the house of his former girl-friend in Lucerne, entered the toilet and took his assault rifle, which he possessed as conscript of the Swiss army, shot the friend of his former spouse and pursued the latter, who rescued herself by jumping to the street from the first floor. Mr. H. followed her and shot randomly at a passer-by before shooting himself. The prosecutor gave the author of this paper the mandate to 
establish an expertise about the mental condition of Mr. H. This could be accomplished quite satisfactorily by interviewing witnesses like the former girlfriend and his kin: Mr. H. had been suffering from the first manifestation of a Paranoid Schizophrenia and suffered from the delusion to be persecuted by his former girl-friend and her friend. If he had survived, from a forensic-psychiatric point of view, he would have been considered not guilty by reason of insanity. All people involved like friends and kin felt somehow relieved to have a medical explanation for this otherwise not understandable and acceptable behaviour of $\mathrm{Mr}, \mathrm{H}$.

\subsubsection{Own Investigation}

Even though the CID had interviewed 40 witnesses such as working mates, supervisors and relatives of Victor B. $\dagger$, the author has chosen to additionally interview three relatives and the family doctor. At the beginning of the interview, the former were informed that as relatives of the perpetrator according to Swiss p. c. they were not obliged to make any statements.

Mr, Zoran B., elder brother of Victor B. $\dagger$, declared on February $25^{\text {th }} 2014$ by phone that there was nothing to comment on. Some facts had been even exaggerated by the media and Victor B. $\dagger$ had in fact been once photographed without his consent in Kronospan and on different occasions he had been contacted by telephone by some unknown persons. The B. family did not wish to comment further on the issue.

Mr. Matthew K., brother-in-law of Victor B. $\dagger$, was ready to give evidence without reservation. He was interviewed on February $27^{\text {th }} 2014$ in the office of the author. Mr. K. was born in Switzerland; his sister Veronica had been born still in Kosovo. His family comes from the same region as the one of Victor B. $\uparrow$. Since his childhood, Victor B. $\dagger$ was just the husband of his sister. Victor B. $\dagger$ was to him a jolly and nice elder colleague, who cared for him. It was him who introduced Mr. K. to the sport of „Kick-boxing“. Victor B. $\dagger$ had great mechanical skills, whatever he was told to repair he could handle. He practiced "Kickboxing", but only for his fitness; he would never compete, because he did not want to endanger his body; His looks were extremely important for him, especially his abdominal muscles ("six packs"). He also practised "Wing-Tsung" - Kung Fu and was a great admirer of the late Bruce Lee ${ }^{2}$. About his earlier biography, Mr. K. knew only that Victor B. $\dagger$ had deserted from an army barrack in Croatia and had demanded Asylum in Switzerland. He might have met Mr. K.'s sister during his leisure time. Mr. $\mathrm{K}$. himself was employed by Kronospan by recommendation of his brother-in-law. The working conditions within Kronospan were excellent; they would tolerate even an alcoholic as employee. Mr K. thinks, there was a change in the behaviour of Victor B. $\uparrow$ about two years ago and this was unequivocally linked to Victor B.'s $\dagger$ opening a Facebook account. As a matter of fact he would think that all messages

\footnotetext{
${ }^{2}$ Movie star and Kung Fu - icon
}

he read had a connection with himself and more and more he thought his style was being imitated. He thought he was in an intimate exchange with Sylvester Stallone ${ }^{3}$ and Vitali Klitschko ${ }^{4}$ through Facebook; both had let him know that he was not a bad man. He felt spied at everywhere, e.g. by the FBI; as a matter of fact that he carried a mask whilst working in his garden and passers-by would tell Victor B. $\dagger$ later that they had observed a stranger working in his garden! There was quite impossible for Victor B. $\dagger$ to use a mobile, since he feared his thoughts were disseminated by the mobile. As a matter of fact, he felt very involved with the Mali-crisis in late 2012 and asked his colleagues to watch what he would arrange there (quite obviously he took himself for a commander of the French intervention force ${ }^{5}$ ). Lunch in Kronospan had become quite stressful for Victor B. $\dagger$ since nowadays everybody had a mobile with him. Mr. K. and even his brothers-in-law had tried to close the Facebook account of Victor B. $\uparrow$ but provoking a very angry reaction. Concerning the extramarital affair of Victor B. $\dagger$, Mr. K. believed there was not much behind it: If Victor $\mathrm{B} . \dagger$ really had had sex with another woman he would have bragged about it. Generally, Mr. K. did not think that the marriage of Victor B. $\dagger$ had been that bad. Concerning the money-lending business Mr. K. had not any knowledge. He thought the B. family in general were quite stuck-up; Victor B. $\dagger$ had been by far the friendliest among them. Mr. K. thought there had been a great chance missed to apprehend Victor B. $\dagger$ before the event, when he visited the emergency ward of the local hospital two months before because of an injury on his foot and behaved in such a strange way, that any medical professional should have taken action. Quite obviously, Victor B.'s † performance at his workplace deteriorated, but he was somehow backed by his colleagues and even his supervisors since everybody thought he was a „nice chap“. Concerning the choice of victims, Mr. K. could not find any logic: There were rumours he had chosen only supervisors but Victor B. $\dagger$ had met some on the factory compound before the event without embarrassing them. Mr. $\mathrm{K}$. thought his choice was at random. For Mr. K. the deed was like a guy who stands on the 5 meters jumping board, closes his eyes, jumps and realizes what has happened. Consequently, he presumed that Victor B. $\dagger$ committed suicide due to a sudden feeling of guilt.

Ms. Verona B., who was born in K., the widow of Victor B. $\dagger$, was quite reluctant to witness, but she eventually was ready to talk in the presence of her therapist on March $3^{\text {rd }}$ 2014. Concerning her origins, she said that her parents had been foreign workers and she had been allowed to join them in the course of family reunion, so since primary school she had been living in Switzerland. Victor B. $\dagger$ had been introduced to her during a family event. It was important to know that among the Kosovar population, only three per cent

\footnotetext{
${ }^{3}$ Action movie star

${ }^{4}$ World heavy weight boxing champion

${ }^{5}$ In autumn of 2012, French armed forces intervened in Mali against a group of Islamist insurgents
} 
were Catholics, but in the region she came from, the town of Gjakove, the share was $50 \%$. It was important to know that among Kosovars it was not only important to marry within its ethnicity but also within their religious belonging. This makes the choice for a migrated catholic Kosovar woman quite small. Among the Catholics there were even two factions, the so called „Mazur" who were rather close to the rest of Kosovo and of whom many were members of the UCK and the consequent Christians and Catholics, who were considered by the former as wimps. Victor B. †'s family belonged to the former, Ms B.'s family to the latter. For both groups, the Kanun ${ }^{6}{ }^{6}$ still mattered as a code of honour. As far as she knew, there was one uncle of Victor B. $\uparrow$ said to be kind of strange but in general one would not discuss such delicate family affairs with the daughter in law! Ms. B. was worried that her frank statements about family affaires would not be appreciated by the B. - family. As far as she knew, Victor B. $\dagger$ had served his military service in 1991 in Croatia as a conscript of the Yugoslavian federal army for nine months before deserting; he certainly had not had any war experience since it was completely out of question that he as a Kosovar was serving with the armed forces during the Yugoslavian crisis. Their marriage had not been an arranged one; at the beginning, they would have had a good time. Her husband had been gentle, gifted and helpful; he would change after the birth of their first child, when he was reluctant to play his part as a father. Marital discord was the consequence. The daily life of the spouses was consequently split; Ms B. had no access to his "Kick-boxing" peers, where women were not welcome at all, anyway. In the run of the years his behaviour changed completely; he came home only late at night and had visited brothels together with his brothers and colleagues. Some years ago he started this money lending business; Ms B. said she ignored where the money came from; she only helped him to write the borrower's notes since he did not know enough German to express himself sufficiently. Ms B. was aware that her husband had considerable trouble at work some four years ago; he had shown her the letter of warning and told her, that he had a quarrel with a colleague at work. At the end, their marriage existed only on paper to maintain the image of an intact family. The said affaire of her husband was at that stage of their marriage without any relevance according to Ms B. As a matter of fact, her husband had been under enormous pressure since he was not a keen money squeezer and even considered selling the house for the credits he was not able to encash. Some episodes of domestic violence had not been registered by the police; as a matter of fact, on the only occasion the police intervened at home had been due to a call by Victor B. $\dagger$ himself. Since autumn 2012 Victor B. $\dagger$ had started to refer daily events to himself; e. g. he stated he being in constant contact with Barrack Obama who asked his advice; he commented on Austrian politics and hinted that he was involved there. Great events like wars and heroes like e. g. Sylvester Stallone or Vitali Klitschko had always impressed him. The last months of his life it had been impossible to communicate normally with him. In December 2012 his supervisor had addressed her asking whether Victor B. $\dagger$ might suffer from a „burnout”. The change of shifts which he had performed for practical reasons just a few months before had probably not been a good idea; maybe he should only work in day shifts. At the beginning of February 2013 Victor B. † showed her the headlines of the tabloid "Blick" about the "problematic bear" M 13, who attacked people in the Alps and hence, even being member of a protected species was now going to be hunted; Victor B. $\dagger$ explained that he literally was M 13 . When she told him that he was completely nuts he would crumple furiously the paper and call her "ignorant psychopath", since he always called her "psychopath ever since she attended psychotherapy. She researched online about the symptoms of her husband and found the term "paranoid". When she approached her brothers-in-law about it, they did not respond. If she, however, had been informed that her husband had three weapons at home, she certainly would have gone to the police. If one of her brothers-in-law told to the police, the B. family kept weapons at home due to their family tradition of hunting she'd call this absurd. On Sunday, $24^{\text {th }}$ of February 2013, just three days before the event, Ms B. visited her parents. Victor B. $\uparrow$ usually had a nap at home. Suddenly he ordered her by telephone to come home. When she arrived there she was frightened since Victor B. $\dagger$ had put the children in their holiday clothes and her husband would carry his dark suit. Ms B. had no idea why. Victor B. † took pictures of his children together with some burning candles. Then he asked Ms B. to accompany him and the children to the church even though throughout his life the church had no meaning to him. The children were very reluctant to comply and the whole procedure was extremely embarrassing to Ms B.; she was scared just like anybody in front of a madman who is able to do anything crazy. In the church he put his children in file and asked Ms B. to film the scene with her mobile. Then he started a speech directed at the Facebook community in which he said he was a good man. He repeated it twice, but was not satisfied. What he eventually would do with this video-sequence, Ms B. does not know. On Wednesday $27^{\text {th }}$ February 2013 in the morning the supervisor of Victor B. $\dagger$ called to ask him to change shift; Victor B. $\dagger$ explained that he had an appointment with his g. p. concerning his daughter. Ms B. did not notice the slightest hint as to what her husband might have planned.

On March $3^{\text {rd }} 2013$ Dr. R., family doctor of the B. family, confirmed that Victor B. $\dagger$ had been on sick leave for a fortnight in November 2012 for a sprain of the ankle. In his medical record Dr. R. never had registered any mental problem of Victor B. $\dagger$.

\footnotetext{
${ }^{6}$ Medieval code of honour in Kosovo
} 


\section{Discussion}

\subsection{Classification of the Event}

With four killed and four injured victims there is no doubt that the event satisfies Dietz's [9] criteria as well as those of Holmes and Holmes [10] to name it Mass Homicide or Mass Murder.

It can also be named "Sensational Homicide". These are, according to Dietz [9], particularly spectacular cases disseminated largely through the media; a typical example was the killing of John Lennon by Tom Hinckley. Of course, almost all Serial and Mass Killings are "Sensational Homicides". This was also the case for Menznau. (By the way: The list $\mathrm{m}$. a. of the dpa [1] is by far not complete if the criteria of Holmes and Holmes for the definition of Mass Murder are applied. In the study $\mathrm{m}$. a. about Homicide-Suicide and lethal domestic violence in the region of Basel [4] there were two cases with three victims).

„Sensational Homicides" can also be instrumentalized: Fritz Leibacher, the perpetrator of the „Zug amok“, had become sort of an icon for frustrated people and trouble-makers, who related to him frequently to give their complaints and demands more emphasis and hence, had to be screened for their putative dangerousness.

Concerning the „Menznau-Case”, Christophe Mörgeli, former MOP and member of the right wing populist $\mathrm{SVP}^{7}$ expressed himself in a blog: „It reads like a script of our failed politics about asylum seekers. Victor B. $\uparrow$ calls himself refugee and migrates from Kosovo to Switzerland. He is allowed to stay, marries, has three children and commits domestic violence, causing police intervention. He breaks a coin-operated machine and with a ruthless attack bereaves a woman.

Three years later he gets a one year's prison sentence on parole. Only four years after his immigration he becomes Swiss citizen. An enterprise which is not aware of these events eventually hires Victor B. $\dagger$. As reward he murders four of his fellow co-workers and injures six more seriously. For days, the media speak about a 'Swiss' as perpetrator. If the so called 'Referendum for the deportation of criminal foreigners' approved by the Swiss people had been in force already in 1995, there would have been no amok in Menznau, since Victor B. $\dagger$ would have been deported as a criminal foreigner. This renders this dreadful event even worse, than it is any way. If the government, the Supreme Court and the parliament still fight against this referendum they are responsible for any further crimes. Instead of embarrassing honourable Swiss marksmen and weapon owners the Swiss nation needs effective politics concerning Asylum-seekers, foreigners and criminals."

Political statements of this kind explain clearly the need to investigate such tragic events by experts.

\subsection{Psychiatric Diagnosis}

Like many of his fellow countrymen, Victor B. $\uparrow$ deserted
1991 from the Yugoslavian federal army at the beginning of the Yugoslavian crisis and asked Asylum in Switzerland. The robbery which he had committed in 1995 after loss of a certain amount of money due to gambling is a single event and does not mean that Victor B. $\uparrow$ had antisocial traits. On the other hand, he stayed working for the same enterprise for more than thirteen years, obviously most time without giving reason to any complaints.

Victor B. $\dagger$ is characterized by his brother-in-law as a "nice chap", but as a bragger too; his wife called him pretentious (,King"); he was concerned with his looks and he was dependent on status symbols; i. e. from a forensic-psychiatric point of view one can ascribe him narcissist traits. His involvement in the money-lending business was probably also an expression of his particular personality. Taken in a nutshell, Victor B. $\dagger$ gives the impression of a nice but naive, if not to say immature and superficial personality, but until short time before the event he did not differ as much from a supposed average human being that the term "personality-disorder" in a clinical sense would apply to him.

Latest by autumn 2012, for his colleagues at work and his kin it became obvious that there was a break in his psychosocial capacities; according to his brother-in-law, these peculiarities became apparent even two years before, when Victor B. $\dagger$ had opened his Facebook account.

Victor B. $\dagger$ did not have any problems with substances, and he was healthy and post mortem, the most common chronic infections which can cause a mental deterioration (HIV, Syphilis) had been excluded. Hence, Victor B. † was suffering from a proper psychiatric (mental) disorder. Some of the peculiarities in the behaviour of Victor B. $\dagger$ are listed below which are significant for the psychiatric expert:

- Victor B. $\dagger$ is convinced, celebrities would imitate his style of clothing and he was in constant exchange through internet with them.

- He is spied at by the FBI

- He said on different occasions, he was photographed in the firm, also when executing degrading work and these pictures were posted on Facebook.

- On the occasion of a visit in the emergency unit of the local hospital he said he was filmed and the video had been posted on Facebook.

- Everywhere, there were cameras recording his activities and the videos were posted on Facebook.

- He would not tolerate switched on mobiles close to him since he feared to be recorded and his thoughts to be disseminated.

- He was convinced to be a major protagonist in the Mali-crisis (end of 2012).

- He took himself to be the so called "Problem bear" M 13, which had been hunted and shot in a southern valley of the Swiss Alps this winter.

- Since autumn 2012 Victor B. $\dagger$ showed a lack of concentration and was no longer reliable at work, so his work had to be controlled on several occasions

- He would start to talk to himself and executed during 
work sudden "Kick-box"- movements without any apparent motive.

- He would mask himself during garden work in order not to be recognized by spies and dark organisations.

These particularities were registered by kin and colleagues of Victor B. $\uparrow$ and were addressed; his brother as well as his brother-in-law tried to persuade him, that his personality was not published without his will in Facebook.

The fear, to be spied at by means of electronic devices by obscure powers or organisations like FBI are clear hints at so called ego-distortions like thought-broadcasting or withdrawal, so called first rank symptoms in the sense of Kurt Schneider, one of the doyen of Schizophrenia research. First rank symptoms are, if they last longer than one month, sufficient to diagnose a schizophrenic disorder. The conviction to be in constant exchange with celebrities is called delusion of reference, another first rank symptom in the sense of Kurt Schneider. The rather elusive idea to be involved in the Mali crisis as main protagonist or to be the „Problem bear“ M 13 are called ,autochthonous delusions" (Wahneinfall). The fear, constantly to be spied at, recorded and to be mocked at in Facebook, corresponds to delusions of persecution. Both these symptoms are so called accessory symptoms in the sense of Kurt Schneider, meaning that they are not sufficient to diagnose Schizophrenia, but are strong hints for the existence of this disorder. Some of his colleagues have reported that Victor B. $\dagger$ would answer on concrete questions in a non-comprehensible way as if he would have not got the idea of the question: This phenomenon is classified as formal thought disorder and called "Danebenreden", another accessory symptom of Schizophrenia. Eventually, Victor B. $\dagger$ would talk to himself, which one can interpret as indirect sign for acoustic hallucinations in the form of ,hearing voices“.

Taken together, Victor B. $\dagger$ would show months before the event so called first rank symptoms for Schizophrenia in the sense of Kurt Schneider, which, if they last longer than four weeks, would prove the diagnosis of Schizophrenia; the registered accessory symptoms as such would not prove the existence of Schizophrenia, but would support this diagnosis. The concept of first rank and accessory symptoms for the diagnosis of Schizophrenia has been taken over by the ICD-10, the diagnostic manual of the WHO. Since the most striking symptom of the Schizophrenia of Victor B. $\dagger$ were his delusions of persecution the diagnosis of Paranoid Schizophrenia, first episode, period of observation less than one year, seem to be justified (ICD-10: F20.09). Unusual, but not a decisive point against this diagnosis is the comparatively late onset of the disorder, namely 42 years (frequency peak of onset usually 24-26 years with male).

The inclusion of the World Wide Web in the delusional world of the concerned could be observed ever since its worldwide introduction end of the last millennium: A 29 years old women would stop all her sexual activities since she felt her activities were recorded by a chip in her brain serving as a webcam and then posted on internet [14]. An also 42 years old man was convinced pornographic recordings of his wife and daughter were posted in internet in order to blackmail him. These are only two examples of some case studies which have been recently published about the topic "Internet delusion". It would be, however, a mistake, to talk about a new psychiatric disorder; on the contrary the World Wide Web is an excellent medium for the concerned to rationally explain the otherwise not comprehensible phenomena which are occurring with them [15]. The Internet seems to have, according to the theory of Emil Kraeppelin, another doyen of Schizophrenia research, a pathoplasticity effect on the contents of the delusions.

Serious acts of violence, perpetrated by schizophrenics might be rare by absolute numbers; they are, however, five to ten times more frequent than with the general population. The incidence of serious acts of violence is much greater among first episode schizophrenias than with chronic cases [16]. Certain cases succeed to keep their psychotic experiences in the dark for a long time; this is referred at as double bookkeeping. Others concerned - like e. g. Victor B. $\dagger$ - act on their delusions. If a person suffering from delusions of persecution starts to blame concrete persons or institutions this might be a sign for an impending act of violence [17].

\subsection{Suicide versus Non Intended Self-killing}

The coroners and forensic experts conclusions were unequivocally that Victor B. $\uparrow$ did not die by an external force; it was him who fired the lethal shot, but it cannot be decided from a coroner's point of view whether this shot was fired intentionally or not.

A quite unequivocal point for suicide was the existence of a suicide letter, but there is none. Points favouring the theory of suicide is the farewell like production of Victor B. $\dagger$, when he photographed his children in the church and gave a speech which seemed to be a kind of justification. This raises the suspicion he might have planned an action he might not survive. Since Victor B. $\dagger$ did not take any measures to conceal his action or to escape, one might ask if he did not plan a kind of "suicide by cop", meaning an act of provocation towards security staff who might shoot at the aggressor. This suicide method might apply for members of a social or religious group for whom self-killing is not tolerated due to religious beliefs [18] We cannot recognize in the modus operandi of Victor B. $\dagger$ any point which would show that he had planned to provoke security staff in this way.

Fact is that many but not all mass murderers die by suicide, some are also killed by security staff $[4,7]$ As m. a. many mass murderers are disgruntled, professionally frustrated loners who want to revenge themselves for a putative or real setback or mortification and quite often close their action by a kind of cathartic suicide [19] In the case of Victor B. $\dagger$ one cannot find any hint at this kind of ,normal psychological "motive; the hypothesis of his brother-in-law; Victor B. $\dagger$ might have been suddenly overwhelmed by feelings of guilt is pure speculation and does not comply with the diagnosis of 
a first episode of Paranoid Schizophrenia. By considering the sociocultural background of Victor B. $\dagger$ one should consider that his background is from south-east Europe where suicide is not accepted at all and what is more, suicide is due to their specific religious beliefs much less frequent among Catholics than among Protestants or Un-denominational.

If one considers the Paranoid Schizophrenia as argument for suicide - up to $10 \%$ of the concerned are said to die by suicide - it must be said that suicide occurs rather in a latter state of the disorder and hence could be addressed as balance suicide when the concerned realize the impact of the disorder on their lives. A not intended shooting by the clinch of Markus A. blocked right hand of Victor B. $\uparrow$ in the lethal direction for him complies very well with the conclusions by the forensic-pathological experts.

Taken together there are from a forensic-psychiatric point of view hardly any points which speak for suicide even though it cannot be ruled out by $100 \%$; the points for a unintended self-killing or an accident of Victor B. $\dagger$ are, however, much more convincing.

\subsection{Legal Capacity Victor $B . \dagger$ and Predictability of the Event}

The delusions of reference and persecution Victor B. $\uparrow$ was quite obviously suffering from are also referred as symptoms of TOC (Threat-Override-Control) [20], which are quite often correlated with serious acts of violence perpetrated by schizophrenic patients.

By analysing the event, one becomes aware how consequently and straight Victor B. $\uparrow$. would have acted; for instance he did not embarrass anyone on his way to the canteen and started only shooting when he had reached the entrance to the canteen, i. e. a closed room, from where there was no escape. He seemingly did not shoot at people at random, too. Such a considerate way of acting, however, does not signify necessarily an unimpaired legal capacity. There is a clear correlation between symptoms of the unequivocally existing Paranoid Schizophrenia and the actions of Victor B. $\dagger$; about the exact motive of or the trigger for the action, however, can only be speculated, but we can compare the case with our own clinical experience or case-reports from the literature: For instance, one could conceive a sudden delusional symptomatology, caused by the call of his supervisor short time before the event, which meant a threat to him and it is quite likely, that Victor B. $\dagger$ held certain members of the Kronospan responsible for his plight caused by his psychotic symptoms. For a perpetrator embarrassed by a TCO-symptomatology the question whether he is able to understand the wrong of his acts is irrelevant, he acts like in self-defence. An acute Paranoid Schizophrenia like in the case of Victor B. $\dagger$ hence justifies from a forensic-psychiatric point of view the stipulation that he did not know the wrong of his acts and that his legal capacity was according to Article $19 \mathrm{sec}$. 1 Swiss penal code annulled.

Concerning the predictability of such an event, it has to be stated that Victor B. $\uparrow$ did not correspond to the profile of the violent frustrated and disgruntled worker as he is specified in the literature about working place violence [21]: Victor B. $\dagger$ had neither repeated convictions for violent crimes in his files, nor did he have a substance problem, nor was he at an impending risk to be fired nor had been omitted with a professional promotion [22]; his fascination for weapons as risk factor was known to nobody except his kin. For his work mates he was just a "nice chap".

Even by applying the short version of the WAVR-21 (Workplace Assessment of Targeted Violence), which is dedicated to non-clinical threat team members like human resources or security and does not use clinical or diagnostic terminology, but emphasizes observable behaviours and workplace contextual factors, showed, that Viktor B. $\uparrow$ only fulfilled 3 out of 12 items [23].

What's more: Viktor B. $\dagger$ had been seen only three months ago by a physician who obviously did not notice anything worrying. Even though a psychiatrist would have examined Viktor B. $\dagger$ on this occasion and had made the correct diagnosis of schizophrenia, Viktor B. $\uparrow$ probably would have not been taken for treatment in this state of the disorder, since Viktor B. † was obviously lacking any form of insight and hence would have not complied with any kind of treatment; treatment against ones will as compulsory residential treatment according to Art. 426 civil codes are only justified in the case of known impending danger for himself or others.

\section{Closing Remarks}

Some unfortunate coincidences might have contributed to the Menznau event:

- A quite common primary personality, perceived by his environment as pleasant ("nice chap").

- Considering his anamnesis, there was a surprising and quick development of a serious psychopathology which would have been clearly identifiable to the expert, but certainly not to the population at large.

- A quite undiscerning professional function, where the deficiencies of Victor B. $\dagger$, which had become apparent, could be compensated by his colleagues.

- The origins of Victor B. $\dagger$ from a cultural background, where psychiatric disorders still are considered as a taboo and are not openly addressed.

- The affinity of Victor B. $\dagger$ for weapons in a country (Switzerland) with a rather liberal legal practice concerning dealing with weapons.

Concerns have been expressed that the focus on the psychopathology of the perpetrators of mass murder might conceal the true problem [24], the easy accessibility of weapons which is in fact a problem in Switzerland, too. In the case of Switzerland, the easy accessibility of weapons concerns, however, far more suicide than homicide or mass murder [25], hence research concerning future cases of mass murders and analysis of past cases seems justified. 
Finally, it should be mentioned that the district attorney in charge of the concerned Sursee County held on $21^{\text {th }}$ of June 2014 a press conference, where the results of their investigations and also the conclusions of the forensic-psychiatric expertise were presented to the public and the concerned. Later, the author was invited by the management of Kronospan, to explain the results of the expertise to their staff. This open communication about the tragic event and especially its explanation from a forensic-psychiatric point of view had been generally appreciated; the effort it took to accomplish the expertise was worth it.

\section{REFERENCES}

[1] Tschanun, Leibacher, Kneubühl: Chronologie der Amoktaten. Online available from http://bazonline.ch/schweiz

[2] Global Study on Homicide 2013 UNODC, Vienna

[3] Y. Auxemery. The Mass Murderer History: Sociodemographic and Psychopathological Characteristics, Suicidal Dimensions, and Media Contagion of Mass Murders, Comprehensive Psychiatry, Vol. 56, 149-154, 2015

[4] D. Lester. Suicide in Mass Murderers and Serial Killers, Suicidology online 2010, Vol. 1: 19-27

[5] J. W. Swanson. Explaining Rare Acts of Violence: The Limits of Evidence from Population Research, Psychiatric Services Vol. 62, 1369-1371, 2011

[6] A. Frei, L. Schönmeier, M. Graf, B. Völlm. , Psychiatrische Praxis, Vol. 38, No. 6, 287-92, 2011

[7] L. Adler. Amok im Spektrum homizidal-suizidaler Handlungen. Suizidprophylaxe, Vol. 37, No. 1, 8-14, 2010

[8] K. Weilbach. Amok - Prävention statt Mythenbildung, Kriminalistik Vol. 61, No. 2, 119-127, 2007

[9] E. P. Dietz. Mass, Serial and Sensational Homicides, Bulletin of the New York Academy of Medicine, Vol. 62, No. 5, $477-491,1986$

[10] R. M. Holmes, S. T. Holmes. Serial Murder 1998, SAGE Publications, 2nd ed, Thousand Oaks, CA

[11] H. Hempel, J. R. Meloy, Th. C. Richards. Offender and Offense Characteristics of a Non-random Sample of Mass Murderers, Journal of the American Academy of Psychiatry and Law Vol. 27, No. 2, 213-225, 1999
[12] E. S. Shneidman. The Psychological Autopsy, Suicide and Life Threatening Behaviour, Vol. 11, No. 4, 325-40, 1981

[13] P. M. Marzuk, K. Tardiff, C. S. Hirsch. The epidemiology of murder-suicide. Journal of the American Medical Association Vol. 267, 3179-3183, 1992

[14] B. Schmid-Siegel, T. Stompe, G. Ortwein-Swoboda. Being a webcam, Psychopathology, Vol. 37, 84-85, 2004

[15] V. Bell, E. Grech, C. Maiden, P. W. Halligan, H. D. Ellis. 'Internet delusions': a case series and theoretical integration. Psychopathology, Vol. 38,144-50, 2005

[16] O. Nielssen, M. Large. Rate of Homicide during the First Episode of Psychosis and After Treatment: A Systematic review and Meta-analysis. Schizophrenia Bulletin, Vol. 36, No. 4, $702-712,2010$

[17] A. Buchanan, A. Reed, S. Wessely, P. Garely, P. Taylor, D. Grubin, G. Dunn. Acting on delusions. II: The phenomenological correlates of acting on delusions. British Journal of Psychiatry Vol. 163, 77-81, 1993

[18] H. R. Hutson, D. Anglin, J. Yarbrough et al. Suicide by cop. Annuals of Emergency Medicine Vol. 32, 665-669, 1998

[19] G. B. Palermo. The Berserk Syndrome: A Review of Mass Murder. Aggression and Violent Behaviour Vol. 2, No. 1, 1-8, 1997

[20] B. G. Link, A. Stueve. Psychotic Symptoms and the Violent/Illegal Behaviour of Mental Patients Compared to Community Controls. In: Monahan J, Steadmann H (Eds.). Violence and Mental disorder, 1994, Developments in Risk Assessment, University of Chicago Press, Chicago

[21] T. A. Fletcher, S. J. Brakel, J. L. Cavanaugh. Violence in the workplace: new perspectives in forensic mental health services in the USA, British Journal of Psychiatry, Vol. 176, 339-344, 2000

[22] H. Bloom, C. D. Webster, R. S. Eisen. ERA-20, Employee risk assessment: A guide for evaluating potential workplace violence perpetrators, 2002, workplace.calm.inc., Toronto

[23] S. G. White, J. R. Meloy. WAVR-21: A structured professional guide for the workplace assessment of violence risk, 2nd ed. San Diego, CA: Specialized Training Services, 2010

[24]. T. MacLeish. Mental Illness, Mass Shootings, and the Politics of American Firearms. American Journal of Public Health, Vol. 105, No. 2, 240-249, 2015

[25] A. Frei, A. Han, M. G. Weiss, V. Dittmann, V. Ajdacic-Gross. Use of army weapons and private firearms for suicide and homicide in the Region of Basle. Crisis, Vol. 27,140-146, 2006 